\title{
AOR
}

Selected Papers of \#AolR2021:

The 22nd Annual Conference of the

Association of Internet Researchers

Virtual Event / 13-16 Oct 2021

\section{ON BROWN BOXES: HIDDEN INTERDEPENDENCE IN UNBOXING VIDEOS}

Zizi Li

University of California, Los Angeles

This project investigates the hidden interdependence in unboxing videos by examining brown cardboard boxes and what I term "brown-boxing" through a case study, focusing on one YouTube unboxing video by makeup influencer Roxette Arisa (2019). Brownboxing is connected to the metaphor of "black-boxing," often refers to powerful yet hidden mechanisms in scientific knowledge production. Like how black-boxing signals the practice of hiding information/labor in technology, brown-boxing points to the mechanisms of concealment along the supply chain. Brown and black boxes are typically discussed in separate spaces, with the former attracting logistics scholars whereas the latter appealing to STS researchers. This paper shows how unboxing videos are valuable to study the overlapping of varying infrastructures and/as labor (Parks and Starosielski 2015) that sustain the digital economy. Utilizing close reading and cultural analysis, I unpack characteristics of unboxing videos and the brown-boxing phenomenon to illustrate the entanglement between influencer media and supply chain. Considering the increasing prevalence of delivery services and influencer marketing, brown boxes can help us explore the mechanism and aesthetics of digital capitalism.

When analyzing Arisa's video, I am confronted with the hypervisible and performative, invisible and highly disposable brown boxes. Conspicuous consumption (Veblen 1899) has exacerbated in the digital influencer era as manifested in the visuality of abundance, with excessive consumption normalized in the name of style. Stacks upon stacks of brown boxes are displayed in an aesthetics of copiousness. Although this is an hour-long video, only around four minutes are related to unboxing brown boxes. The core of the video attends to the inner packages, showcasing products, and expressing gratitude to brands. Brown box is a shipping exterior that physically protects the objects of value inside. It is the aesthetics of these products and the copious way of life that is ultimately being projected through unboxing videos. Inner boxes are things on display, decoupled from their sources and journeys. Brown boxes' uniformity generally performs

Suggested Citation (APA): Li, Z. (2021, October). On Brown Boxes: Hidden Interdependence in Unboxing Videos. Paper presented at AoIR 2021: The 22nd Annual Conference of the Association of Internet Researchers. Virtual Event: AolR. Retrieved from http://spir.aoir.org. 
visual secrecy that adds to the magic of delivery service experienced by consumers, divorcing it from the labor performed by logistics workers.

I see unboxing videos as a process genre (Skvirsky 2020) that capitalizes on the literal secrecy offered by brown boxes made possible the production of such media to increase the aura of value of the items inside. While labor is present, it remains either hypervisible or invisible as influencer media spectacularizes work. The demystified process are ones that can be aestheticized and capitalized, such as taking apart the gimmicky-looking box stacks and the suspense-and-joy of unwrapping packages. The revealed processes tend to generate affective relationships between the influencer and their followers through this shared commercial intimacy (Abidin and Thompson 2012), which also indirectly increase the influencer's social-cultural-economic capital. The ones that remain invisible involve exploited labor across sectors. If being unraveled, these concerns will devalue the brands, YouTube channel, and the influencer's overall portfolio. As such, unboxing videos embody a parasitic relationship between influencers and brands in a way that maintains the capitalistic future by uplifting the ideals of consumption via aesthetics of excess and selective concealment of labor time/process.

There are many kinds of invisible labor necessitated by virtual work and digital economy (Cherry 2016). Unboxing videos offer a particular venue to consider creator labor in relation to logistics work. Arisa's filming was interrupted by a doorbell with more boxes delivered by a UPS worker. Arisa recounts the brief encounter and includes some footage. The worker is a silenced and invisible figure; we cannot hear or see him. But we hear Arisa - who was holding the delivered boxes and a camera-awkwardly saying "oh, hi, thank you, sorry." Nonetheless, we can feel the presence of the delivery worker via this brief off-frame interaction captured in the video. It is in these split seconds that the magic of click-and-arrive as an ideal technology of zero work is dispelled. While "all productive activities are measured against the magic standard" that any product can be produced more effortlessly and any process can be run more smoothly, packages do not just magically appear on the doorstep (Gell 1992). The production and distribution of goods run on a massive and diverse workforce across the supply chain even in the present "automated" society. The captured brown-boxing phenomenon points to the containerization of supply chain capitalism in the last-mile delivery, involving workers responsible for distributing goods to customers in warehouses, fulfillment centers, retail stores, and delivery vehicles (Bonancich and Wilson 2008).

In this light, I propose the need to unpack unboxing videos and other influencer media in a relational-materialist framework that highlights the interdependence between "creative" and "physical" labor in and beyond the digital realm. Although supply chain is rarely discussed in influencer scholarship, how influencers interact with logistical labor/infrastructure do unexpectedly show up with evidence of interdependence unintentionally seeping into audiovisual media. The visually-and-audibly invisible UPS worker in Arisa's video, for instance, is channeled through the rupture of her filming process. Byam (2015) sees relational labor as uncompensated immaterial work microcelebrities continuously do to build and maintain ongoing interpersonal and group relationships. Sharing this affective moment of interruption and feeling of "being judged" by others (Arisa 2019) generates a sense of intimacy, authenticity, and connectivity. But influencer work is more than brand management and audience engagement. This brief 
documented encounter between Arisa and the delivery worker reveals a kind of relational labor engaged by influencers that goes beyond building digital relationship with followers, and as intermediaries between brands and consumers. Without a properly functioning logistics industry, influencers would not be able to unbox, review, and market products timely on different platforms.

As mentioned earlier, brown-boxing refers to the practice of concealment in the supply chain capitalism. Not only are goods hidden by brown boxes and the process of delivery service remain mostly unseen, but logistics workers' bodies are also often buried by extreme productivity quotas and physically blocked by huge stacks of heavy boxes in the warehouse floors and delivery trucks. This study suggests that unboxing videos as a process genre has the potential of visualizing the interdependent relationships in influencer economy by presenting relational labor performed in the interactions between influencers and logistics workers.

\section{References}

Abidin, C., and Thompson, E.C. (2012). "Buymylife.com: Cyber-femininities and commercial intimacy in blogshops," Women's Studies International Forum 35:467-477. http://dx.doi.org/10.1016/j.wsif.2012.10.005

Arisa, R. (2019, Sep 8). MY BIGGEST PR UNBOXING HAUL EVER *not clickbait* [Video]. YouTube. https://youtu.be/iOlLSgcBsag

Bonancich, E., and Wilson, J.B. (2008). Getting the Goods: Ports, Labor and the Logistics. Cornell UP.

Byam, N.K. (2015). "Connect With Your Audience! The Relational Labor of Connection," The Communication Review 18(1):14-22. https://doi.org/10.1080/10714421.2015.996401

Cherry, M.A. (2016). Virtual Work and Invisible Labor. In Crain M., Poster W., and Cherry M. (Eds.), Invisible Labor: Hidden Work in the Contemporary World (pp.71-86). U-of-California Press.

Gell, A. (1992). The Technology of Enchantment and the Enchantment of Technology. In Coote H. and Shelton A. (Eds.), Anthropology, Art, and Aesthetics (pp.40-63). Clarendon.

Parks, L., and Starosielski, N. (Eds.) (2015). Signal Traffic: Critical Studies of Media Infrastructures. U-of-Illinois Press.

Skvirsky, S.A. (2020). The Process Genre: Cinema and the Aesthetic of Labor. Duke UP.

Veblen, T. (1899). The Theory of the Leisure Class. Pantianos. 